\title{
Comunidade pomerana e uso de agrotóxicos: uma realidade pouco conhecida
}

\author{
Pomeranian community and the use of pesticides: \\ an unknown reality
}

\author{
Ludmilla da Silva Viana Jacobson ${ }^{1}$ \\ Sandra de Souza H acon ${ }^{1}$ \\ Luciana Alvarenga ${ }^{1}$ \\ Roberta Argento Goldstein ${ }^{1}$ \\ Carmen Gums ${ }^{3}$ \\ Daniel Forsin Buss² \\ Luciana Ribeiro Leda²
}

${ }^{1}$ Departamento de Endemias, Escola Nacional deSaúde Pública Sérgio

Arouca, Fundação O swaldo Cruz. Rua Leopoldo Bulhões 1480, M anguinhos. 21041210 Rio deJaneiro RJ. ludmillaviana@yahoo.com.br ${ }^{2}$ Departamento deBiologia, Instituto Osvaldo Cruz,

Fundação Oswaldo Cruz.

${ }^{3}$ Secretaria deSaúdedeSanta Maria de etibá.
Abstract The objective of this article is to characterize social and economically the Pomeranian community from "Alto Santa M aria" in the municipality of Santa M aria de Jetibá at Espírito Santo State and investigate the main factors of pesticides exposure in rural community. A crosssectional study was carried out interviewing 151 members of a rural Pomeranian community using a semi-structured questionnaire. The analysis was based in descriptive statistics and logistics regression models. The results revealed that the majority of the community members own their land. The child participation in agricultural activities is a tradition in the Pomeranian culture. The use of pesticides by this community began in the 80s sincethen; different types of pesticides have frequently been used by rural residents. The logistic regression models that associate the presence of some health problem with how the land is cleaned, pesticides usage, pesticides application frequency and the use of protection equipment, showed that the chance of an individual to present some health problem is related with the use of pesticides. Another regression model showed that the education level is an important factor to the use of protection equipment. The Pomeranian community studied has some cultural habits that contribute for the exposure of pesticides.

Key words Pesticides, Pomeranian community, Rural worker
Resumo 0 objetivo deste trabalho foi caracterizar socioeconomicamente a comunidade pomerana do Alto Santa M aria, localizada no município deSanta M aria de etibá (ES) einvestigar os princi pais fatores de exposição aos agrotóxicos. Tratase de um estudo transversal realizado a partir de um questionário semi-estruturado, reunindo informações de 151 famílias. A análise foi baseada em estatísticas descritivas e modelos de regressão logística. Os resultados revelaram que a maioria dos membros da comunidade é o proprietário da terra. A participação das crianças nas atividades agrícolas é uma tradição da cultura pomerana. 0 uso de agrotóxicos nas lavouras nesta comunidade começou na década deoitenta e, desde então, diferentestipos deagrotóxicos são frequentementeusados pela população rural. Os modelos de regressão logística queassociam a presença de al gum proble ma desaúde com o tipo de limpeza da terra, uso de agrotóxicos, frequência de aplicação dos agrotóxicos e uso de equipamento de proteção mostraram que a chance de um indivíduo apresentar algum problema de saúde está relacionada com o uso de agrotóxicos e o grau de escolaridade é um fator importante para o uso de equipamentos de prote ção. A comunidade pomerana estudada possui hábitos culturais que contribuem para a exposição aos agrotóxicos.

Palavras-chave Agrotóxicos, Comunidadepomerana, Trabalhador rural 
Introdução

A origem da agricultura é datada de aproximadamente dez mil anos atrás, e no decorrer dos séculos, muitas modificações técnico-produtivas foram incorporadas com o objetivo de aumentar a produção de alimentos. 0 processo de modernização tecnológica iniciado nos anos cinquenta com a chamada "revolução verde", somado ao discurso da "modernização da economia rural", modificou profundamente as práticas agrícolas, gerou mudanças tecnológicas nos processos de trabal ho, aumentou a produtividade e, mais recentemente, a agricultura tornou-se uma importante atividade econômica, através da geração de divisas na exportação brasileira. Esses incrementos na produção agrícola afetaram diretamente a saúde humana, principalmente dos trabal hadores rurais e dos ecossistemas, com o crescimento descontrolado de pragas como insetos, fungos e roedores, expulsou a fauna e a flora de seus habitats, com a destruição dos ecossistemas e a sua substituição por novas áreas de expansão de atividades agropecuárias ${ }^{1}$. Com a modernização da agricultura, os trabalhadores rurais passaram a estar expostos a riscos diversificados e desconhecidos?

0 elevado e indiscriminado uso de agrotóxicos no país tem contribuído para a contaminação ambiental eo aumento das intoxicações, principalmente ocupacionais. Estudos de caracterização da exposição em regiões de agricultura familiar têm evidenciado a contaminação do ambiente de moradia, principalmente a poeira domiciliar, solo, ar ealimentos. Isto se deve à forma dearmazenamento dos agrotóxicos, queno meio rural se dá na sua mai oria no local de moradia, e ao uso de roupas contaminadas no campo, que são usadas dentro de casa. O utro problema refere-se à proximidade das áreas de cultivo, onde 0 agrotóxico éaplicado, das residências. Esses problemas, somados à exposição do trabalhador rural, constituem-senos principais problemas de saúde pública no meio rural brasileiro e em outros países da América Latina ${ }^{3-6}$.

Dados secundários sobre intoxicações por agrotóxicos podem ser encontrados no Sinitox (Sistema N acional de I nformação Tóxico-Farmacológica); porém, Soares et al. ${ }^{7}$ chamam atenção para a subnotificação dos casos de intoxicação. Uma análise da base de dados do Sinitox, referente ao período de 1999 a 2003, identificou 64.313 casos de intoxicação com 1.148 óbitos por agrotóxicos de uso geral, dos quais cerca de $42 \%$ dos casos de intoxicação com 747 óbitos foram por uso agrícola ${ }^{8}$. Em 2003, na área rural brasileira, foram registrados 2.519 casos de envenenamento por agrotóxicos de uso agrícola, sendo que a Região Sudeste foi a de maior número de casos (1.423) em relação às demais regiões. São Paulo e Espírito Santo foram os estados desta região com maior número de casos registrados na área rural, 1.237 e 105 casos, respectivamente?

A exposição ambiental aos agrotóxicos para a população urbana se caracteriza principalmente por uma exposição crônica, que inclui também a segurança alimentar, ou seja, baixas doses por um longo período de exposição. O Programa deAnálises de Resíduos de Agrotóxicos em Alimentos (PARA), realizado pela ANVISA, analisou entre 2001 e 2004 cerca de quatro mil amostras de alimentos. 0 resultado mostrou que $28,5 \%$ dos resíduos encontrados nos alimentos são irregulares e que, destes, $83 \%$ correspondem a agrotóxicos que não possuem uso autorizado para as culturas. Somente $17 \%$ possuem uso autorizado, mas encontrados em quantidades acima do limite máximo de resíduos permitidos pela legislação ${ }^{10}$. Outro problema relacionado à exposição ambiental em outras regiões do país refere-se à pulverização por aviões e tratores, que em geral acarretam a contaminação do ar, podendo atingir longas distâncias através da dispersão dos produtos químicose, consequentemente, contaminando os recursos hídricos, a biota e solos ${ }^{11}$.

0 presente estudo foi realizado em uma comunidade pomerana no Alto Santa M aria, município de Santa M aria de Jetibá, região serrana do Espírito Santo (Figura1). Trata-se de uma comunidade que preserva suas tradições culturais, principalmente a língua pomerana. Ao Iongo dessa pesquisa, foi possível observar o papel da língua enquanto mantenedor da identidade cultural. $\mathrm{O}$ povoamento da região de Santa M aria de Jetibá começou com a chegada, em 1857, deimigrantes vindos da Pomerânia. Atéo ano de 1873, pouco mais de 2.000 pomeranos se estabeleceram no Espírito Santo ${ }^{12}$. Hoje, os descendentes dos imigrantes que residem na região serrana do estado são considerados uma das últimas comunidades no mundo onde se fala o pomerano. A área de estudo foi o povoado do Alto Santa M aria, no entorno da microbacia do córrego dos Gonçalves, afluente do rio Santa M aria da Vitória. A principal atividade econômica do povoado é a agricultura familiar, que representa uma fortee expressiva tradição, na qual os filhos dos agricultores iniciam o seu trabalho na roça muito jovem, antes dos dez anos de idade ${ }^{13,14}$. Outra característica da região é a alternância da 
Escola Agrícola, onde os alunos frequentam as aulas em uma semana e, na seguinte, são incentivados a ficar com a família para que tenham maior convivência com a atividadeagrícolae dela participem mais ativamente. Esse povoado caracteriza-se por uma população rural, onde vivem 151 famílias, representando aproximadamente 720 habitantes. 0 presente estudo objetiva caracterizar socioeconomicamente a comunidade pomerana do Alto Santa M aria e investigar os principais fatores de exposição aos agrotóxicos para esta comunidade.

\section{Métodos}

0 presente estudo é parte integrante do Programa Institucional da Água da Fiocruz, que realizou um diagnóstico socioambiental da comunidade pomerana no povoado do Alto Santa M aria, como parte integrante dos estudos de gestão da bacia do rio Santa M aria da Vitória no período de 2005/2006. Trata-se de um estudo transversal, aprovado pelo Comitê de Ética da Fio-
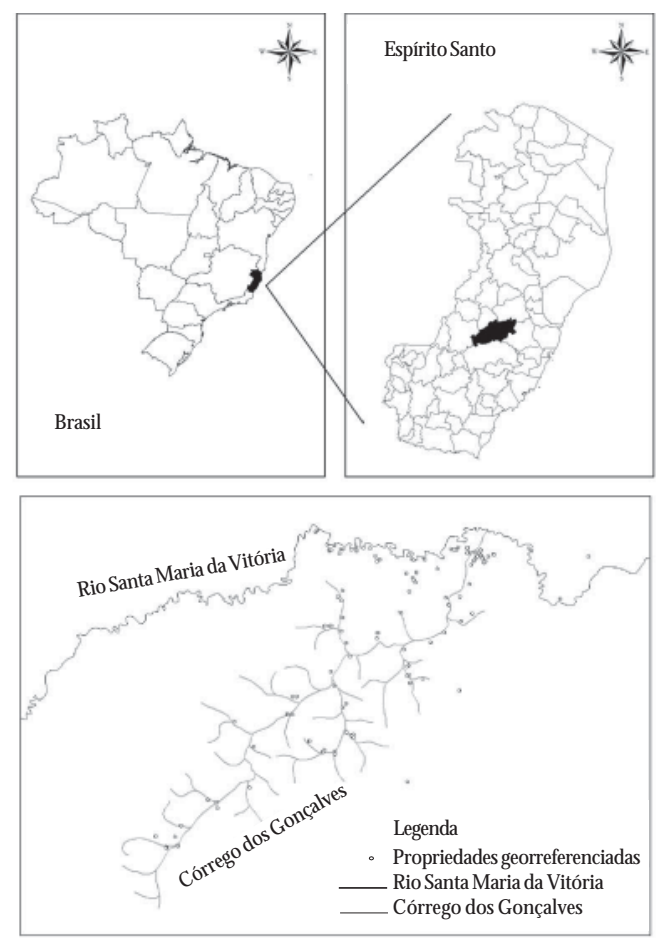

Figura 1. Localização da área de estudo.
cruz/EN SP. A abordagem metodológica do estudo foi pautada na experiência desenvolvida a partir do projeto Geo-Saúde ${ }^{15}$. Esta abordagem integra a partici pação dos atores sociais locais na identificação dos problemas ambientais prioritários para a comunidade. N esta abordagem, os atores sociais interessados no processo de parceria comunidade/projeto reúnem-se juntamente com a equipedo projeto para discutirem os principais problemas ambientais e de saúde da comunidade local, assim como as possíveis barreiras de impedimento do projeto e possíveis conflitos. Reuniões foram realizadas na escola, nas residências de lideranças locais e em eventos da comunidade, com o objetivo de discutir os problemas socioambientais locais e seu nível de importância para a comunidade. Com base nas informações levantadas na primei ra etapa, foi elaborado em 2005 um questionário semi-estruturado, aplicado na comunidade residente no entorno da microbacia do Córrego dos Gonçalves, no povoado do Alto Santa M aria. As perguntas do questionário foram apresentadas e discutidas com os líderes locais, que revisaram e propuseram adequação do vocabulário, apropriado para um melhor entendimento da comunidade na condução das entrevistas, e ampliação de algumas questões. 0 questionário foi inicialmente testado em uma amostra de quinze entrevistas, sendo um adulto de cada propriedade. Com base no resultado do teste piloto, as questões foram novamente revisadas de acordo com as considerações levantadas pelos atores sociais locais, resultando em um questionário semi-estruturado subdividido em seis módulos:

(1) sociodemográfico eeconômico, com perguntas sobre o perfil do entrevistado e de suas condições de moradia, bem como sobre o processo de trabal ho e sua renda familiar;

(2) saúde, com perguntas sobre atendimento médico, principais agravos à saúde e tratamento recebido;

(3) hábitos pessoais, com questões relacionadas aos hábitos defumar, uso de bebidas alcoólicas ehigiene pessoal;

(4) inquérito alimentar, com perguntas sobre os alimentos consumidos e frequência do consumo;

(5) produção agrícola, com perguntas sobre tamanho da propriedade, tipo de culturas produzidas, destino da produção, criação deanimais e uso de agrotóxicos; e

(6) percepção socioambiental, com perguntas direcionadas para os problemas da comunidade, assim como a percepção do entrevistado 
em relação à exposição ocupacional e ambiental aos agrotóxicos.

Em relação ao uso de agrotóxicos, o questionário abordou questões sobre: (a) histórico de utilização dos agrotóxicos (tipo por cultura e doença); (b) práticas de uso; (c) uso de equipamento de proteção; (d) frequência deaplicação e (e) destino das embalagens.

Para o presente artigo, foram analisadas as seguintes variáveis:

(1) para a caracterização das condições socioeconômicas: sexo, faixa etária, grau deescolaridade, renda familiar e atividade ocupacional;

(2) presença de al guma doença (variável construída a partir da pergunta "Tem algum proble ma de saúde?"); e

(3) produção agrícola (presença de assistência técnica na prática agrícola, uso de agrotóxicos, tipos de agrotóxicos por cultura, uso de equipamento de proteção, tipo de limpeza da área cultivada, destino das embalagens dos produtos químicos efrequência deaplicação dos agrotóxicos).

Entrevistas individuais foram realizadas em um único adulto selecionado al eatoriamente de cada uma das 151 propriedades, totalizando-se 151 entrevistas. Não houve recusa à participação na pesquisa; porém, houve recusa de parte dos entrevistados em responder al gumas questões do questionário, como renda e aquelas relacionadas à exposição ao agrotóxico.

Todas as famílias do povoado atenderam aos critérios de inclusão para a realização das entrevistas, a saber: ter como principal atividade econômica a agricultura familiar nos últimos cinco anos, ter quinze anos ou mais de idade. Todos os entrevistados assinaram um termo de consentimento, concordando com a participação na pesquisa. As entrevistas, uma por família, foram realizadas por dois agentes do Programa da Saúde da Família do município, ambos pomeranos, após o treinamento com membros da equipe do projeto para aplicação dos questionários. Quando necessário, o termo e o questionário foram traduzidos para o pomerano verbalmente pelos entrevistadores. Todas as propriedades foram georreferenciadas. Após a coleta de dados, os questionários foram digitados erevisados econstruído o banco de dados.

A análise exploratória dos dados permitiu caracterizar o processo detrabal ho eestimar, através de modelos de regressão logística, o risco de determinados fatores de exposição. Foram elaborados cinco model os de regressão logística. Em quatro modelos, a variável resposta foi a presença de algum problema de saúde (a variável dico- tômica foi elaborada a partir da pergunta "Q ual - seu problema desaúde?" eforam incluídas apenas as doen ças potencialmente associadas ao uso e exposição aos agrotóxicos) e as variáveis explicativas foram o tipo de capina da área cultivada (manual, herbicida, manual e herbicida), o uso de agrotóxico, frequência de aplicação dos agrotóxicos e o uso de al gum equipamento de proteção. Além disso, um model o de regressão logística simples foi ajustado para verificar a significância da relação entreo uso de equipamento de proteção e o grau de escolaridade.

\section{Resultados}

O município deSanta M aria de etibá está localizado na região serrana do Estado Espírito Santo, a oitenta quilômetros da capital. É o maior produtor de hortaliças do estado. A olericultura representa a atividade mais bem distribuída no município, alcançando aproximadamente $80 \%$ das 3.000 propriedades familiares existentes. A região é importante produtora de café, de eucalipto e de mel. Há também atividades de ecoturismo, agroindústria, psicultura, floricultura, fruticultura e produção de tubércul ${ }^{12}$.

Em 2000, o IDH do município foi de 0,724, ocupando a posição 2.550 ạ do ranking dos municípios, enquanto que o IDH do estado foi de 0,765 , ocupando a 11 a posição do ranking dos estados (dentre os municípios do Espírito Santo, Santa M aria de Jetibá ocupa a 41 a posição no ranking dos municípios). 0 município apresenta uma população de aproximadamente 32.224 habitantes eumaárea total de $734 \mathrm{~km}^{2}$, com uma densidade demográfica de $43,9 \mathrm{hab} / \mathrm{km}^{2}{ }^{16}$. A população da área urbana é de 5.103 habitantes, o que significa que cerca de $80 \%$ da população do município vivem em propriedades rurais, predominantemente de base familiar. Essas propriedades têm em média vinte hectares e estão inseridas em áreas de $M$ ata Atlântica.

Em relação à população entrevistada do Alto Santa M aria, 84\% são donos das propriedades e a forma de trabal ho que prevalece na comunidade é o trabalho por conta própria. Segundo esta pesquisa, apenas $5 \%$ dos entrevistados possuem propriedades acima de vinte hectares. Esses dados confirmam que a população do Alto Santa M aria possui pequenas propriedades, tendo em vista que a área referente a um minifúndio ( $p e$ quena propriedade) equivale em média a dezenove hectares ${ }^{17}$. A produção desta comunidade se caracteriza como agricultura de subsistência, 
o excedenteé vendido na maioria das vezes para atravessadores ou para o comércio de regiões vizinhas, como, por exemplo, a Grande Vitória.

Segundo os dados levantados através das entrevistas, o uso de agrotóxicos na região chegou no início da década de oitenta, com a implantação de energia elétrica e a construção de sistemas de irrigação. Até este período, a maior parte do povoado não conhecia o uso de agrotóxicos. 0 processo produtivo sofreu importante transformação; a agricultura antes voltada para a produção de café, milho, arroz, cana-de-açúcar, feijão e agricultura de subsistência, foi substituída pela olericultura, com a possibilidade de aumento de rentabilidade na produção agrícola. Dessa forma, o uso intensivo de agrotóxicos se iniciou com a implantação da olericultura e, consequentemente, 0 controle das pragas.

A Tabela 1 apresenta as características socioeconômicas dos entrevistados. A maioria dos entrevistados encontra-se na faixa etária da população economicamenteativa entre 18 a 49 anos.

Tabela 1. Características socioeconômicas da população entrevistada do Alto Santa M aria, 2005.

\begin{tabular}{lrr}
\hline \multicolumn{1}{c}{ Características } & $\mathrm{n}$ & \multicolumn{1}{c}{$\%$} \\
\hline Sexo & & \\
$\quad$ M asculino & 81 & 53,6 \\
Feminino & 70 & 46,4 \\
$\quad$ Total & 151 & 100,0 \\
Faixa etária & & \\
Até 17 & 12 & 7,9 \\
18 a 34 & 60 & 39,7 \\
35 a 49 & 38 & 25,2 \\
50 ou mais & 41 & 27,2 \\
Total & 151 & 100,0 \\
Escolaridade complementar & & \\
Não sabe ler e nem escrever & 8 & 5,3 \\
Escreve o nome & 17 & 11,3 \\
Primeiro grau incompleto & 108 & 71,5 \\
Primeiro grau completo & 11 & 7,3 \\
Segundo grau incompleto & 2 & 1,3 \\
Segundo grau completo & 2 & 1,3 \\
Nível superior & 3 & 2,0 \\
Total & 151 & 100,0 \\
Renda (R\$) & & \\
Até 299,00 & 81 & 55,9 \\
300,00 a 699,00 & 44 & 30,3 \\
700,00 ou mais & 20 & 13,8 \\
$\quad$ Total & 145 & 100,0 \\
Vínculo de trabalho & & \\
Sem contrato & 130 & 86,1 \\
Contrato rural & 21 & 13,9 \\
Total & 151 & 100,0 \\
\hline & & \\
\hline
\end{tabular}

Dos entrevistados, cerca de $88 \%$ não sabem ler ou possuem até o 10 grau incompleto. A população mais jovem apresentou grau de escolaridade mais elevado que os mais idosos. Em relação à renda familiar, mais de $50 \%$ das famílias vivem com menos de um salário mínimo. A principal fonte de renda desta comunidade é a atividade da agricultura familiar, distribuída por todos os membros da família nas funções de capinar, pulverizar o agrotóxico, plantar, arar e colher, na qual aproximadamente $80 \%$ trabalham há mais de dez anos nesta atividade.

Em relação à produção agrícola, os resultados revelaram que o uso de assistência técnica, oferecida pela Secretaria da Agricultura do município, é pouco presente na região; apenas 16\% referiram já ter usado algum tipo de assistência. Segundo os dados levantados nos questionários, a limpeza da área cultivada é realizada com capina manual (37\%), com herbicidas ( $12 \%$ ) e com ambas as técnicas (51\%).

Com relação ao uso de agrotóxicos, cerca de $60 \%$ dos entrevistados afirmaram que utilizam agrotóxicos na produção agrícola; as justificativas são 0 controle de pragas, 0 aumento da produção e a tradição familiar. Segundo a percepção da comunidade, entende-sepor tradição familiar atransformação da técnica do uso da terra por agroquímicos, iniciada no final da década de oitenta, através da pressão externa da região. Os 40\% restantes desenvolvem a agricultura orgânica. A palavra"veneno" foi a mais utilizada pelos entrevistados para se referirem aos agrotóxicos. Q uanto à frequência de aplicação dos agrotóxicos, 44\% declararam que fazem a aplicação semanalmente. Além disso, segundo os agricultores, a aplicação é intensificada no verão, devido à maior intensidadedeinfestação de pragas e perda do agrotóxico, através do carreamento do produto com as fortes chuvas.

Em relação ao uso de equipamento de proteção individual (EPI), 60\% dos entrevistados declararam não utilizar. Do total de entrevistados, apenas $16 \%$ utilizam o EPI completo. Para os que não usam proteção, as principais justificativas foram a fal ta derecurso financeiro para comprar o equipamento eo incômodo que o equipamento proporciona. Em relação ao destino das embalagens dos agrotóxicos, as campanhas realizadas pelo Instituto de Defesa Agropecuária e Florestal (IDAF), no sentido de sensibilizar a comunidade em relação à importância do retorno das embalagens, se refletiram nos resultados das entrevistas, visto que $50 \%$ dos que responderam a esta questão devolvem a embalagem ao fornecedor (Tabela 2). 


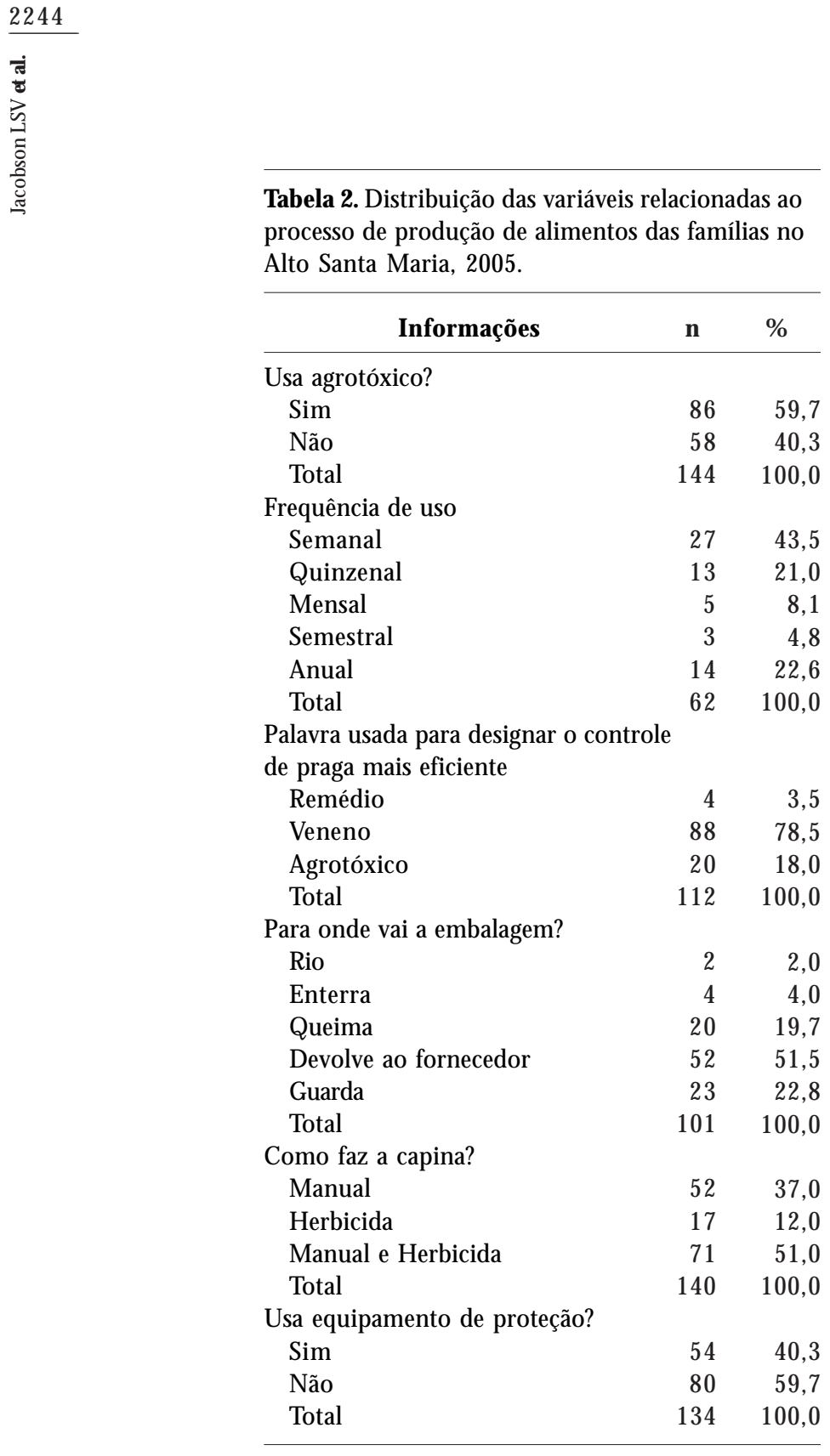

Segundo os dados obtidos no questionário sobre a produção de alimentos, a região do Alto Santa M aria possui cultivos temporários e permanentes; cerca de $60 \%$ utilizam ambas as formas de cultivo, já que a maioria planta mais de um tipo de cultura. A produção de alimentos local é consumida por $98 \%$ dos moradores locais. As justificativas para esta afirmativa foram a qualidade dos seus produtos e a necessidade do autosustento. Dentre os produtos cultivados nas lavouras, destacam-se 0 alho, milho, feijão, verduras, café, cebola, cenoura, jiló, repolho, beterraba e berinjela (Tabela 3).
No que se refere ao uso dos agrotóxicos na região do Alto Santa M aria, foram relatadas 23 marcas diferentes. Dentre as marcas relatadas, $42 \%$ têm a finalidade de fungicida, $38 \%$, de inseticida e $21 \%$, de herbicida. Os agrotóxicos mais citados foram o Gramoxone, Roundup (ambos são herbicidas) e o Decis (inseticida). Em relação à classe toxicológica, $8 \%$ dos agrotóxicos usados nas culturas são produtos extremamente tóxicos (classe I), 17\% são produtos altamente tóxi$\cos$ (classell), 50\% são produtos moderadamente tóxicos (classe III) e 25\% são produtos pouco tóxicos (classe IV) (Tabela 3).

Em relação aos principais problemas de saúde da comunidade referidos pel os entrevistados, mais da metade da população do Alto Santa M aria reclama de verminoses, problemas de pele e esquistossomose. Os próprios entrevistados referem-se aos problemas de pele relacionando-os com a exposição aos agrotóxicos, o que de certa forma confirma a percepção deste grupo analisado. Com relação à resposta do entrevistado quanto ao seu problema de saúde, $48 \%$ deles referiram problemas de saúde potencialmenterelacionados com o uso e exposição aos agrotóxicos.

0 primeiro modelo logístico elaborado foi um modelo simples (modelo 1), que analisou a presença de algum problema de saúde com o tipo de capina, ou seja, com a limpeza do terreno. Para este modelo, os resultados revelaram que a probabilidade de um indivíduo ter algum problema de saúde é maior entre os que fazem a limpeza da área cultivada usando herbicida, em que o risco da exposição é aumentado em $267 \%$ em relação aos que fazem a capina manualmente. Quando 0 modelo éajustado pela variável "uso de agrotóxi$\cos ^{\prime \prime}$ (modelo 2) esta chance é potencializada e passa a ser $639 \%$ maior. Outro fator de risco encontrado foi a frequência de aplicação dos agrotóxicos; o modelo 3 aponta para o aumento do risco deum indivíduo ter algum problema de saúde quando a frequência da aplicação é semanal. Por outro lado, o uso de equipamento de proteção (modelo 4) funciona como um fator de proteção, visto que a chance de um indivíduo ter algum problema de saúde fazendo a capina com herbicida diminui para $257 \%$ em relação à categoria de referência. 0 modelo 5 relaciona o uso de equipamentos de proteção com o grau de escolaridade e o resultado revela que, quanto maior 0 grau de escolaridade, maior éa chance de um indivíduo usar o equipamento de proteção emenor o risco de exposição aos agrotóxicos (Tabela 4). 
Tabela 3. Agrotóxicos utilizados na região do Alto Santa Maria, 2005.

\begin{tabular}{|c|c|c|c|c|c|}
\hline Nome comercial & Classe* & $\begin{array}{c}\text { Classe } \\
\text { toxicológica* }\end{array}$ & Ingrediente ativo* & Grupo químico* & Cultura referida \\
\hline Afalon & Herbicida & III & linuron & uréia & cebola, cenoura e alho \\
\hline Agrinose & Fungicida & IV & oxicloreto de cobre & inorgânico & jiló, berinjela e pimentão \\
\hline Amistar & Fungicida & IV & azoxistrobina & estrobilurina & beterraba \\
\hline Karate & Inseticida & II & lambda-cialotrina & piretróide & cebola e repolho \\
\hline Decis & Inseticida & III & deltametrina & piretróide & $\begin{array}{l}\text { alho, beterraba, repolho, tomate, } \\
\text { cebola, jiló, berinjela, pimentão e } \\
\text { verduras }\end{array}$ \\
\hline Dithane PM & Fungicida & III & mancozebe & ditiocarbomato & $\begin{array}{l}\text { repolho, alho, batata inglesa, } \\
\text { batatinha, feijão, jiló, berinjela e } \\
\text { pimentão }\end{array}$ \\
\hline Expurgran & Inseticida & IV & malation & organofosforado & repolho \\
\hline Score & Fungicida & I & difenoconazol & triazol & beterraba \\
\hline Folisuper $600 \mathrm{BR}$ & Inseticida & I & parationa-metílica & organofosforado & abobrinha, feijão, repolho e verduras \\
\hline Fungiscan $700 \mathrm{PM}$ & Fungicida & IV & tiofanato-metílico & benzimidazol & jiló \\
\hline Gramoxone & Herbicida & II & $\begin{array}{l}\text { dicloreto de } \\
\text { paraquate }\end{array}$ & $\begin{array}{l}\text { Bipiridílio } \\
\text { paraquat }\end{array}$ & café, milho e feijão \\
\hline M anzate & Fungicida & III & mancozebe & $\begin{array}{l}\text { Ditiocarbomato } \\
\text { mancozeb }\end{array}$ & $\begin{array}{l}\text { vagem, alho, pepino, pimentão, jiló, } \\
\text { abobrinha, batata, cebola, repolho, } \\
\text { couve-flor, batatinha e tomate }\end{array}$ \\
\hline Pirate & Inseticida & III & clorfenapir & análogo de pirazol & tomate, repolho e beterraba \\
\hline Roundup & Herbicida & IV & glifosato & glicina substituída & verduras, café, alho e cenoura \\
\hline Ridomil Gold MZ & Fungicida & III & $\begin{array}{l}\text { mancozebe + } \\
\text { matalaxil-M }\end{array}$ & $\begin{array}{l}\text { ditiocarbomato } \\
+ \text { acilaninato }\end{array}$ & repolho, pimentão e cebola \\
\hline Rumo GDA & Inseticida & II & indoxacarbe & oxadiazina & repolho, beterraba, tomate e verduras \\
\hline Cuprozebe & Fungicida & III & $\begin{array}{l}\text { mancozebe }+ \\
\text { oxicloreto de cobre }\end{array}$ & $\begin{array}{l}\text { ditiocarbomato } \\
\text { + inorgânico }\end{array}$ & berinjela \\
\hline Polytrin & Inseticida & III & $\begin{array}{l}\text { cipermetrina }+ \\
\text { profenofós }\end{array}$ & $\begin{array}{l}\text { piretróide }+ \\
\text { organofosforado }\end{array}$ & repolho e beterraba \\
\hline Folicur PM & Fungicida & III & tebuconazol & triazol & berinjela e abobrinha \\
\hline Vertimec $18 \mathrm{CE}$ & Inseticida & III & abamectina & avermectinas & $\begin{array}{l}\text { abobrinha, pimentão, beterraba, } \\
\text { repolho, berinjela e pepino }\end{array}$ \\
\hline Ronstar $250 \mathrm{BR}$ & Herbicida & II & oxadiazona & oxadiazolona & cenoura e alho \\
\hline Tracer & Inseticida & III & espinosade & espinosinas & repolho \\
\hline Curzate BR & Fungicida & III & $\begin{array}{l}\text { cimoxanil + } \\
\text { mancozebe }\end{array}$ & $\begin{array}{l}\text { acetamida }+ \\
\text { ditiocarbomato }\end{array}$ & jiló, berinjela e pimentão \\
\hline
\end{tabular}

*Fonte: ANVISA

N ota: Os agrotóxicos ea cultura apresentados na tabela foram referidos pelos trabal hadores rurais.

\section{Discussão}

Os resultados deste estudo corroboram o impacto da exposição aos agrotóxicos como uma variável que contribui diretamente para os efeitos à saúde humana. Segundo Soares et al. ${ }^{18}$, os trabal hadores rurais que vivem constantemente em contato com os agrotóxicos estão sujeitos às intoxicações agudas com graves consequências para a saúde.

O uso dos agrotóxicos na região de estudo é intenso, como em outras regiões do Brasil. A re- gião, como em outros estudos ${ }^{19,20}$, sofreu incentivos do mercado para a compra e utilização dos agrotóxicos como uma forma de aumentar a produção, acompanhada da transformação do processo de produção agrícola no modo de subsistência para a fase de comercialização dos produtos produzidos como uma fonte de renda.

Segundo os dados do IBGE ${ }^{16}$ sobre a população do município de Santa M aria de Jetibá, a taxa de analfabetismo funcional da população dequinzeanose maiséde $32,5 \%$ (urbana, $24,3 \%$ e rural, $34,3 \%$ ) e a média de anos de estudo éde 


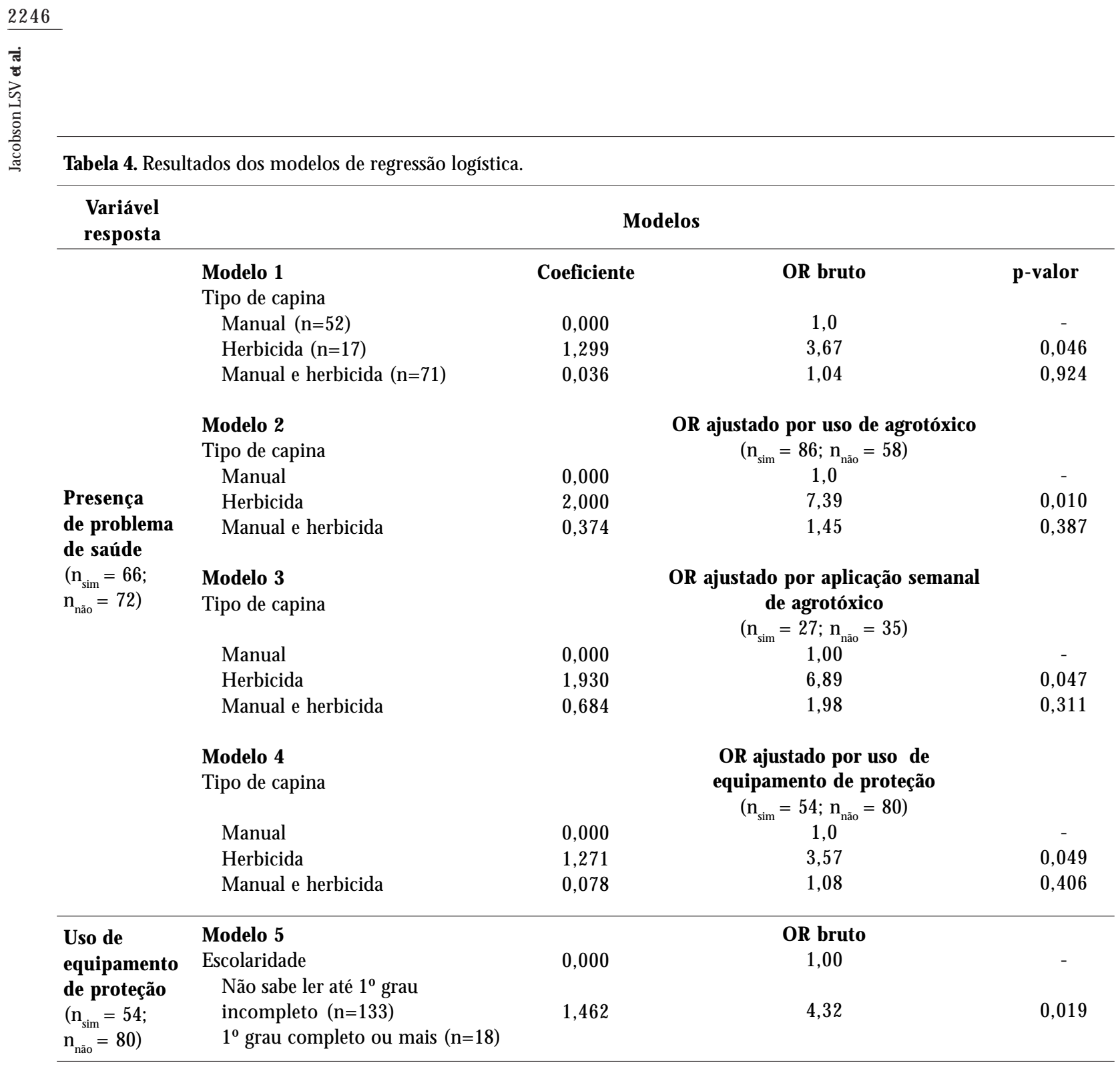

4,4 apenas (urbana, 6,2 e rural, 3,9). A renda mensal familiar per capita correspondea: atémeio salário mínimo - 28\% da população; mais de meio a um salário mínimo - 31\% da população; e de um a dois salários mínimos - $23 \%$ da população. Comparando-se as características socioeconômicas da população estudada do Alto Santa M aria com a situação da zona rural brasileira, sobretudo do município de Santa M aria de Jetibá, observa-se que a baixa escolaridade e renda refletem no modo de vida da região ${ }^{21}$

A prática agrícola e o uso dos agrotóxicos apresentaram-se, nos relatos dos trabalhadores rurais, fortemente associados às tradições familiares: "A prendi com a minha família, aqui já usava" (agricultor, 24 anos).
A ausência de técnicos especializados para auxiliar e instruir os agricultores rurais sobre as doses e tipos de agrotóxicos mais eficazes para cada cultura aumentam os riscos de intoxicações, devido ao uso inadequado de determinados produtos químicos. $\mathrm{N}$ a região, os agricultores costumam misturar sobras de agrotóxicos, preparando o que eles chamam de "calda", para pulverização, cuja prática pode potencializar os efeitos dos agrotóxicos à saúde humana. Os fatores responsáveis pela contaminação por agrotóxicos, principalmentedos organoclorados, atualmente se devem em grande parte pela inexistência de aconsel hamento técnico adequado dos órgãos responsáveis pela indicação agronômica, além da falta de fiscal ização e aplicabilidade das 
leis, a base educacional ecampanhas de esclarecimento em relação aos riscos da exposição aos agrotóxicos $18,21,22$.

A palavra veneno utilizada pelos entrevistados ao se referirem aos agrotóxicos evidencia uma maior percepção de seus efeitos à saúde humana. 0 presente estudo corrobora a pesquisa realizada por $\mathrm{Gomide}^{23} \mathrm{em}$ diversas regi ões do Brasil, na qual mostrou que os agricultores que usam a palavra "remédio" apontam como positivo para a planta a aplicação dos agrotóxicos, enquanto que os que utilizam o termo "veneno" têm maior clareza sobre os riscos à saúde humana e ao meio ambiente.

Os agrotóxicos mais utilizados na região do estudo são muito tóxicos para a exposição humana. A absorção do produto químico ocorre tanto pelo trato digestivo quanto pelas vias respiratórias e cutâneas, sendo o contato dermal a principal via de exposição dos agrotóxicos. 0 Roundup, um herbicida utilizado na região na substituição da capina manual, cujo princípio ativo é o glifosato, pode provocar problemas dermatológicos. 0 herbicida Gramoxone pode provocar lesões hepáticas, renais e fibrose pulmonar irreversível ${ }^{10}$. Uma situação quepodeagravar ainda mais a exposição da população do Alto Santa M aria a este tipo de agrotóxico éa presença de lesões cutâneas nos membros inferiores dos agricultores, onde a absorção do produto é mais rápida. 0 inseticida Decis, do grupo químico piretróide, pode causar, dentre outras enfermidades, irritações nos olhos, alergias de pele e asma brônquica. $\mathrm{N}$ a região, são comuns queixas referentes aos problemas que possivelmente envolvem a saúde mental ${ }^{20}$, tais como depressão, perda de memória, que podem estar relacionados ao uso de agrotóxicos pertencentes ao grupo químico dos organofosforados, pois atuam como inibidores irreversíveis das colinesterases, especialmente a acetilcolinesterase no sistema nervoso central3,10. Outras queixas da comunidade referentes ao estado de saúde são os problemas respiratórios e os dermatológicos.

Através desta pesquisa, constata-se que a comunidade entrevistada no povoado do Alto Santa M ariaencontra-sevulnerável à exposição e, consequentemente, às intoxicações por agrotóxicos devido ao nível de toxicidade dos produtos utilizados, falta de equipamentos de proteção adequados, baixa escolaridade, ausência de um programa de extensão rural que sensibilize os trabal hadores para os riscos associados à saúde em decorrência do uso de determinados agrotóxicos, além do tempo e frequência de exposição. Esses acha- dos corroboram estudos realizados em diferentes regiões do país e em nível internacional3,4,6,7,18,24.

$\mathrm{Na}$ comunidade pomerana entrevistada, 0 grau de escolaridade e a renda são alguns dos determinantes para 0 aceite sobre 0 uso do EPI. Segundo Evans e Kantrowitz ${ }^{25}$, as características socioeconômicas têm relação significativa com fatores de risco ambientais. 0 presente estudo corrobora os resultados de um estudo realizado no município de Magé, região metropolitana do Rio de Janeiro, com agricultores expostos aos agrotóxicos, que mostrou que as variáveis socioeconômicas influenciam nos níveis de intoxicação, principalmente o grau de escolaridade ${ }^{26}$. A baixa escolaridade e a falta de informação sobre os riscos de exposição aos agrotóxicos dificultam o entendimento das informações presentes nos rótulos ${ }^{14}$. Esses resultados também foram evidenciados na pesquisa com a população pomerana, agravada pelo fato de uma parte dos agricultores no povoado do Alto Santa M aria não falarem o português.

0 desconforto causado pelo equipamento de proteção individual apontado pelos agricultores do Alto Santa M aria também foi destacado em um estudo realizado no município de Teresópolis, região serrana do Rio de janeiro, que avaliou as características dos trabalhadores rurais ${ }^{7}$.

Diante dos resultados e discussão apresentados neste artigo, éimportanteressaltar a necessidade de campanhas direcionadas para a educação ambiental da população de estudo, com ênfaseno risco de intoxicação devido ao uso inadequado dos agrotóxicos e da proximidade das moradias das áreas de cultivo.

Com relação às limitações deste estudo, destacam-se o pequeno número de entrevistas para a análise estatística. Em relação à linguagem, embora nem todos os entrevistados falassem 0 português, essa dificuldadefoi suprimida devido a entrevista ter sido realizada por agentes de saúde do município que falavam o pomerano. Uma outra dificuldade foi 0 acesso ao local, considerando as condições topográficas e a falta de infraestrutura das estradas de acesso à região do Alto Santa M aria.

Como verificado em outras regiões do país, o município de Santa M aria de Jetibá também não está preparado para atendimento de casos de intoxicação por agrotóxico, ou seja, não há recursos humanos treinados, nem infraestrutura laboratorial que permita confirmar o diagnóstico de intoxicação. Como consequência, os registros deintoxicação por agrotóxicos ou atendimento ambulatorial são subnotificados, o que 
neste caso dificultam o conhecimento real da intoxicação por agrotóxico no país.

As transformações observadas nos últimos anos no processo do trabalho rural do país, a partir dos avanços tecnológicos, tornaram 0 agricultor cada vez mais subordinado às variações do mercado, contribuindo para a degradação ambiental e os agravos à saúde humana, em consequência do aumento, qualitativo e quantitativo, indiscriminado deagrotóxicos no país. N este sentido, Santa M aria de Jeti bá representa um retrato do que se verifica no país em termos de uso e exposição aos agrotóxicos.

\section{Colaboradores}

LS Viana trabalhou na concepção e redação do texto, revisão bibliográfica e análise estatística; SS H acon, na concepção e redação do texto e na concepção do estudo; L Alvarenga e C Gums, na concepção do estudo e trabal ho de campo, treinamento dos agentes de saúde; RA Goldstein, na estruturação do questionário, banco de dados e trabalho de campo; DF Buss e LR Leda participaram do trabalho de campo e análise de dados.

\section{Agradecimentos}

Selene Hammer Tesch (agente comunitária de saúde do Alto Santa M aria) e Debora Tesch (representante do grupo de jovens do Alto Santa M aria); Tatiana Berger, da Secretaria de Saúde de Santa M aria de J etibá; Prefeitura de Santa M aria de Jetibá e suas secretarias; Vilmar Waiandt (tradutor). Também à Vice-presidência de M eio Ambiente da Fiocruz pelo apoio financeiro ao projeto através do edital temático de 2003 do Programa Institucional de Pesquisa em Saúde e Ambiente, Conhecimento eação integrando ambiente, vida e sociedade, da Fiocruz/PDTSP. 


\section{Referências}

1. Armas ED, M onteiro RT, Amâncio AV, Correa RM L, Guercio M A. Uso de agrotóxicos em cana-de-açúcar na bacia do Rio Corumbataí e o risco de poluição hídrica. Quim N ova 2005; 28(6):975-982.

2. Silva JM, Novato-Silva E, Faria HP, Pinheiro TMM. Agrotóxico e trabalho: uma combinação perigosa para a saúde do trabalhador rural. Cien Saude Colet 2005; 10(4):891-903.

3. Chisté AM D, Có WLO. Percepção ambiental de uma comunidade pomerana em relação ao uso de agrotóxicos. Natureza on line [periódico na Internet] 2003 [acessado 2007 jan 15]:1(1):[cerca de 5 p.]. Disponível em: http://www.naturezaonline.com.br.

4. Giuffrida A, Fiunes R, Savedoff WD. Occupational risks in Latin America and the Caribbean: economic and health dimensions. Health Policy and Planning 2002; 17(3):235-246.

5. Miranda AC, Moreira JC, Carvalho R, Peres F. Neoliberalismo, uso de agrotóxicos e a crise da soberania alimentar no Brasil. Cien Saude Colet 2007; $12(1): 7-14$.

6. Oliveira-Silva JJ, Alves SR, Meyer A, Perez F, Sarcinelli PN, M attos RCOC, M oreira JC. Influência de fatores socioeconômicos na contaminação por agrotóxicos, Brasil. Rev. Saúde Pública 2001; 35(2):130-135.

7. Soares WL, Freitas EAV, Coutinho JAG. Trabalho rural e saúde: intoxicações por agrotóxicos no município de Teresópolis - RJ. Rev. Econ. Sociol. Rural 2005; 43(4):685-701.

8. Bochner R. Sistema Nacional de Informações Tóxico-Farmacológica (SINITOX) e as intoxicações humanas por agrotóxicos no Brasil. Cien Saude Colet 2007; 12(1):73-89.

9. Sistema Nacional de Informações TóxicoFarmacológicas. [site da Internet]. [acessado 2007 jan]. Disponível em: http://www.fiocruz.br/sinitox/ agrotoxicos/agrotoxicos.htm

10. Agência Nacional de Vigilância Sanitária.[site da Internet]. [acessado 2007 jan]. Disponível em: http:/ /www.anvisa.gov.br/toxicologia/index.htm

11. Stopelli IM BS, Magalhães CP. Saúde e segurança alimentar: a questão dos agrotóxicos. Cien Saude Colet 2005; 10(Supl.):91-100.

12. Prefeitura M unicipal de Santa M aria de Jetibá. [site da Internet]. [acessado 2007 ago em 24]. Disponível em: http://www.pmsmj.es.gov.br

13. Bahia J. A "lei da vida": confirmação, evasão escolar e reinvenção da identidade entre os pomeranos. Educ. Pesq. 2001; 27(1):69-82.

14. Fehberg LCC, Lutz LV, Moreira AH. Agrotóxicos e seus efeitos sócio-culturais: zona rural do Valão de São Lourenço, Santa Teresa, ES, Brasil. Natureza on line 2003; 1(2):51-55.
15. Hacon SS, Schutz G, Bermejo PM. Indicadores de saúde ambiental: uma ferramenta para a gestão integrada de saúde e ambiente. Cad. Saúde Coletiva 2005; 13:45-66.

16. Instituto Brasileiro de Geografia e Estatística. Censo Demográfico 2000. [site da Internet]. [acessado 2006 dez]. Disponível em: http://www.ibge.gov.br

17. Adas M. Panorama Geográfico do Brasil. São Paulo: M oderna; 1987.

18. Soares W, Almeida RMVR, M oro S. Trabalho rural e fatores de risco associados ao regime de uso de agrotóxicos em M inas Gerais, Brasil. Cad. Saúde Pública 2003; 19(4):1117-1127.

19. Peres F, Lucca SR, Ponte LMD, Rodrigues KM, Rozemberg B. Percepção das condições de trabalho em uma tradicional comunidade agrícola em Boa Esperança, Nova Friburgo, Rio de Janeiro, Brasil. Cad. Saúde Pública 2004; 20(4):1059-1068.

20. Peres F, Rozemberg B, Lucca SR. Percepção de riscos no trabalho rural em uma região agrícola do Estado do Rio de Janeiro, Brasil:agrotóxicos, saúde e ambiente. Cad. Saúde Pública 2005; 21(6):1836-1844.

21. Moreira JC, Jacob SC, Peres F, Lima JS, Meyer A, Oliveira-Silva JJ, Sarcinelli PN, Batista DF, Egler M, Faria M VC, Araújo AJ, Kubota AH, Soares MO, Alves SR, M oura CM, Curi R. Avaliação integrada do impacto do uso de agrotóxicos sobre a saúde humana em uma comunidade agrícola de Nova Friburgo, RJ. Cien Saude Colet 2002; 7(2):299-311.

22. Sobreira AEG, Adissi PJ. Agrotóxicos: falsas premissas e debates. Cien Saude Colet 2003; 8(4):985-990.

23. Gomide M. Agrotóxico: que nome dar?. Cien Saude Colet 2005; 10(4):1047-1054.

24. Hoppin JA, Adgate JL, Eberhart M, Nishioka M \& Ryan PB. Environmental Exposure Assessment of Pesticides in Farmworker Homes. Env H ealth Perspect 2006; 114(6):929-35.

25. Evans GW, Kantrowitz E.Socioeconomic status and health: the potential role of environmental risk exposure. Annual Review of Public Health 2002; 23:303-331.

26. Peres F, Oliveira-Silva JJ, Della-Rosa HV, Lucca SR. Desafios ao estudo da contaminação humana e ambiental por agrotóxicos. Cien Saude Colet 2005; 10(Supl.):27-37.

Artigo apresentado em 13/11/2007

Aprovado em 18/11/2008

Versão final apresentada em 10/09/2008 